\title{
Ação quimioprotetora do chá verde em ratos tratados com Dietilnitrosamina
}

\author{
Green tea chemoprotection in rats treated with \\ Diethylnitrosamine
}

\author{
Wanderlei Onofre Schmitz ${ }^{*}$; Dirceu Estevão²; Rubens Cecchini²; Alexandre \\ Saito $^{2}$; Halha Ostrensky Saridakis ${ }^{3}$
}

\section{Resumo}

O chá verde (Camellia sinensis) e seus principais componentes, as catequinas, apresentam várias atividades biológicas, dentre elas a ação antioxidante e quimioprotetora contra agentes hepatotóxicos, como a dietilnitrosamina (DEN), um conhecido agente citotóxico. Este trabalho tem como objetivo avaliar e compreender os mecanismos da ação do extrato do chá verde (ECV), como agente antioxidante e quimioprotetor. Foram realizados testes in vivo com ratos Wistar machos utilizando o ECV a $2 \%(2 \mathrm{mg} / 100 \mathrm{~mL})$ via oral, como única fonte de água, durante 35 dias. Para verificar a capacidade antioxidante e quimioprotetora do ECV utilizou-se a DEN $(200 \mathrm{mg} / \mathrm{kg})$ como agente lesivo. Os resultados indicam que o chá verde, nas doses próximas as que são ingeridas pela população, não é capaz de inibir significativamente a lesão causada pela alta dose da DEN, mas os resultados indicaram uma tendência à quimioproteção, sugerindo que o chá verde pode agir como substância preventiva mesmo em baixas doses, frente a um agente hepatotóxico classicamente conhecido.

Palavras-chaves: Camellia sinensis. Quimioprotetor. Catequinas. Dietilnitrosamina.

\begin{abstract}
Green tea (Camellia sinensis) and its main components, the catechins present several biological activities such as: antioxidant and chemoprotective action against hepatotoxic agent as diethylnitrosamine (DEN), a known cytotoxic substance. This work has the objective to evaluate and understand the green tea extract (GTE) mechanisms of action as a chemoprotector agent. Therefore, tests in vivo with Wistar rats using GTE $2 \%(2 \mathrm{mg} / 100 \mathrm{~mL})$ was taken orally as the only source of water for 35 days. To verify the antioxidant and chemoprotective capacity of GTE, DEN $(200 \mathrm{mg} / \mathrm{kg})$ was used as a lesion agent. The results indicate that green tea if the dosage close to the ones taken by the population is not able to expressively inhibit the lesion caused for the high dose of DEN, but the results indicated a tendency to chemoprotection, suggesting to green tea may act as a prevention substance even in low dosage in presence of a classically known hepatotoxic agent.
\end{abstract}

Key words: Camellia sinensis. Chemoprotector. Catechins. Diethylnitrosamine.

\footnotetext{
1 Graduado em Farmácia Bioquímica (UEL); Especialista em Análises Clínicas (UEL); Especialista em Didática e Metodologia do Ensino (UNOPAR); Mestre em Patologia Experimental (UEL). E-mail: wandererita@ig.com.br

2 Departamento de Ciências Patológicas, Universidade Estadual de Londrina.

3 Departamento de Microbiologia, Universidade Estadual de Londrina, Londrina-PR, Brasil.

*Autor para Correspondência
} 


\section{Introdução}

O chá verde é uma infusão das folhas da planta Camellia sinensis (L.) Kuntez, rica em polifenóis, sendo as catequinas seus principais componentes terapêuticos. O chá verde possui atividades: antioxidante, quimioprotetor, anticancerígeno e antiinflamatório. As catequinas encontradas no chá verde são: epicatequina (EC), epigalocatequina (EGC), 3-galato--epicatequina (ECG), 3-galato-epigalocatequina (EGCG). Esses componentes correspondem a aproximadamente $26 \%$ dos compostos derivados das folhas secas do chá verde (RICE-EVANS; MILLER; PAGANGA, 1996; COOK; SAMMAN, 1996).

As catequinas do chá verde obedecem aos princípios da farmacocinética e da farmacodinâmica que envolve a absorção, biodisponibilidade, metabolização hepática via enzimas do citocromo P450 (CYP) e conjugação com glutation, além da excreção por via renal (SCOTT; ELMER, 2002). Tanto as catequinas como os agentes pré-carcinogênicos sofrem metabolização, com conseqüente ativação pelas mesmas enzimas do citocromo P450 (Fase I). Maliakal, Coville e Wanwimolruk (2001) investigaram a hipótese de modulação dessas enzimas metabolizadoras da Fase I e a atividade das enzimas da Fase II (conjugação), após o consumo de chá verde. O teste foi realizado em ratos Wistar, e foi observado que em todos os grupos de animais que consumiram o chá verde as enzimas CYP 1A2 e a glutationa-Stransferase citosólica apresentaram um aumento de suas atividades. O equilíbrio entre a Fase I das isoenzimas do citocromo $\mathrm{P} 450$, que transformam as substâncias absorvidas pelo organismo em produtos intermediários, e as isoenzimas da Fase II, que conjugam estes produtos com o glutation levando a desintoxicação do organismo. Essa fase é fundamental para a excreção dessas substâncias tóxicas antes que sejam capazes de causar lesão ao organismo. É neste ponto onde a ação do chá verde pode ajudar a modulação das enzimas hepáticas, diminuindo os riscos de se desenvolver um câncer quimicamente induzido.

Chenetal.(1997) eZhu, Chen e Li (2000) tentaram compreender a absorção, distribuição, metabolismo e eliminação das catequinas pelo organismo. Segundo esses autores, dentre as catequinas a EGCG é a mais absorvida e se distribui por todos os tecidos e possui maior meia vida. Utilizando ratos Sprague-Dawley que receberam extrato do chá verde, Zhu, Chen e Li (2000) obtiveram resultados que indicam uma concentração plasmática máxima das catequinas em 2 horas após o aporte oral. Lee et al. (2002) demonstraram tempos de meia-vida de 3 a 4 horas para EGCG e 2 horas para EC/EGC, sendo que todas as catequinas foram excretadas em 8 horas pelos animais.

O chá é eficiente no combate dos radicais livres, que têm importante papel na lesão de membranas por lipoperoxidação, aterosclerose, envelhecimento precoce e carcinogênese (HALLIWELL; GUTTERIDGE, 1999). Para comprovar a ação antioxidante do chá verde Yokozawa et al. (2000) e Cai et al. (2002) testaram a ação do chá verde frente ao 2,2-azobis-amidinopropano-diidroclorido (AAPH), que é um composto capaz de gerar radicais livres do tipo peroxil. Esses radicais causam lipoperoxidação de membranas especialmente nos microssomos de fígado de ratos, pois os microssomos possuem alto grau de ácidos graxos poliinsaturados na sua constituição. O chá mostrou ser eficaz na inibição da lipoperoxidação, atuando como um scavenger de radicais livres gerados pelo AAPH. O chá também protege o organismo contra a ação do óxido nítrico $(\cdot \mathrm{NO})$ que leva a formação do peroxinitrito, inibindo a sua produção pela óxido nítrico sintase induzida (iNOS) (PAQUAY et al., 2000). Nakagawa e Yokozawa (2002) demonstraram que o chá verde pode agir sobre •NO e ânion superóxido $\left(\mathrm{O}_{2} \cdot-\right)$, confirmando sua ação anti-radical livre, além de demonstrar que a adição de um grupo galato e hidroxilas à estrutura do anel aromático das catequinas aumentavam a sua capacidade de atuar como scavenger de radicais livres. 
Skrzydlewska et al. (2002) realizaram um estudo in vitro para confirmar a ação antioxidante das catequinas, utilizando um composto gerador de radicais livres para causar lesão e quebra do DNA. As catequinas, quando incubadas com o composto gerador de radicais livres e o DNA, foram capazes de proteger o DNA da ação dos radicais livres, sendo a EGCG o composto mais efetivo. Yanagimoto et al. (2003) demonstraram que a atividade inibitória do chá era dose dependente e esses resultados confirmaram os dados encontrados na literatura.

O consumo de chá verde é associado diretamente com o baixo risco de doenças cardiovasculares. Essa relação pode ser explicada pela sua capacidade de prevenir a oxidação da LDL, principal causadora da aterosclerose (MIYAZAWA, 2000). Sung et al. (2000) estudaram o efeito antioxidante do chá verde em 10 voluntários saudáveis (23-25 anos). Nesse estudo, os pacientes tinham sua capacidade antioxidante total do plasma dosada e logo após, recebiam doses de $150 \mathrm{ml}, 300 \mathrm{ml}$ e $450 \mathrm{ml}$ de chá verde (2,5 g, 5,0 g e 7,5 g de chá). Após 120 minutos do consumo do chá, foi avaliada novamente a capacidade antioxidante total do plasma. Os resultados encontrados indicaram um aumento de $6,2 \%, 12,0 \%$ e $12,7 \%$ da capacidade antioxidante total do plasma nos pacientes que consumiram 150 $\mathrm{ml}, 300 \mathrm{ml}$ e $450 \mathrm{ml}$ de chá verde, respectivamente.

Chen et al. (2004) testaram a eficiência dos polifenóis do chá verde como quimioprotetores, e, para isso, realizaram um experimento em ratos tratados com tetracloreto de carbono $\left(\mathrm{CCl}_{4}\right)$. No experimento foram utilizadas como parâmetros de avaliação da proteção, as análises dos cortes histopatológicos, a peroxidação de lipídios e RNA mensageiro para óxido nítrico sintase. Administração do chá e seus polifenóis conduziram a uma diminuição dose-dependente em todos os parâmetros bioquímicos e histopatológicos reduzindo a severidade dos danos causados pelo CC14.

Testes in vivo em rato indicam que a lesão oxidativa causada pelo metabolismo de agentes cancerígenos participa na produção e desenvolvimento de tumores. $\mathrm{O}$ dano oxidativo dá ênfase à hepatocarcinogênese e à indução de lesões pré-neoplásicas relacionados ao modelo de iniciação-promoção. Ratos que sofreram um prétratamento com o antioxidante quercetina, uma hora antes da iniciação com a dietilnitrosamina, apresentaram uma diminuição da lesão oxidativa e conseqüentemente da peroxidação de lipídios. Esses resultados mostram uma correlação direta entre peroxidação de lipídio e hepatocarcinogênese e fortalece a utilização de agentes antioxidantes para prevenção da carcinogênese in vivo (SÁNCHEZPÉREZ et al., 2005).

Devido a trabalhos que apontam o chá verde como um agente protetor e com atributos benéficos para a saúde humana, o Instituto Nacional do Câncer dos EUA iniciou um plano para a utilização deste chá como quimiopreventivo do câncer (SIDDIQUI et al., 2004).

Diante do exposto, este trabalho pretende avaliar o efeito quimioprotetor do extrato do chá verde in vivo frente ao agente hepatotóxico Dietilnitrosamina (DEN), quantificando a lesão celular através da dosagem da atividade enzimática das transaminases (AST/ALT), lipoperoxidação das membranas através da quantificação das substâncias reativas ao ácido tiobarbitúrico (TBARS) e o ensaio de FOX (complexo Fe(III)-xilenol laranja) e do estudo histopatológico do fígado dos ratos submetidos ao teste.

\section{Material e métodos}

\section{Reagentes}

Dietilnitrosamina (DEN), cloreto férrico $1 \mathrm{mM}$ $\left(\mathrm{FeCl}_{3}\right)$, ácido ascórbico $1 \mathrm{mM}$ Sulfeto de ferro, 3,3'bis [N,N-di (carboximetil) amino-metil]-O-cresol sulfoneftaleÍna (xilenol laranja), Sigma Chemical Company, USA; Formaldeído, ácido sulfúrico, metanol HPLC e ácido tioderivado da maloniluréia 
(TBA 1\%) Merck. Kit de aspartato aminotransferase (AST) e alanina aminotransferase (ALT) (Laborlab). Os demais reagentes e compostos utilizados foram da mais alta pureza disponível no mercado.

\section{Preparo do extrato das folhas de Camellia sinensis}

O extrato etanólico de chá verde (ECV) foi preparado a partir de $300 \mathrm{~g}$ de folhas secas de $C$. sinensis (L.) Kuntez, adquiridas da Quimer Ervas Medicinais. Após a extração por 24 horas com álcool etílico absoluto, o produto foi filtrado em papel de filtro e concentrado em rota vapor com temperatura de $40^{\circ} \mathrm{C}$ (ELOFF, 1998).

\section{Animais de experimentação}

Ratos Wistar machos, pesando entre 200 e $250 \mathrm{~g}$, foram mantidos em gaiolas de polietileno com tampa de aço inox, em grupos de seis animais por gaiola. A ração granulada e água foram oferecidas ad libitum. A temperatura ambiente foi mantida entre 20 e $25^{\circ} \mathrm{C}$, a umidade relativa e um baixo nível de ruído foram mantidos dentro das condições ideais. $\mathrm{O}$ fotoperíodo foi controlado para prover luz das 06:00 às 18:00 horas.

\section{Delineamento experimental}

Após uma semana de aclimatação, os animais foram distribuídos aleatoriamente em gaiolas coletivas e divididos em quatro grupos. Grupo 1 - grupo controle; Grupo 2 - animais inoculados com DEN; Grupo 3 - animais tratados com ECV; Grupo 4 - animais tratados com ECV e inoculados posteriormente com DEN. Os animais foram tratados por 35 dias com ECV 2\% via oral ad libitum (grupos G3 e G4), inoculados com dose única via intraperitoneal de $200 \mathrm{mg} / \mathrm{kg}$ de DEN (grupos G2 e G4) e sacrificados por deslocamento cervical 48 horas após inoculação da DEN. O sangue foi coletado por punção cardíaca para obtenção do plasma para a quantificação AST/ALT e fragmentos do fígado foram retirados para análise histológica. Parte da amostras de fígado foi mantida em freezer $\left(-80^{\circ} \mathrm{C}\right)$ para a quantificação das substâncias reativas ao ácido tiobarbitúrico (TBARS) e para o ensaio de FOX (complexo Fe(III)-xilenol laranja) (ESTEVÃO; SAITO; GUALTIERI, 2002).

\section{Determinação da atividade da AST e ALT}

O plasma obtido foi usado para quantificação da atividade enzimática das enzimas aspartato aminotransferase (AST) e alanina aminotransferase (ALT), utilizando-se a análise colorimétrica para transaminases padronizada pela Laborlab Sistemas Diagnósticos Ltda (REITMAN; FRANKEL, 1957).

\section{Quantificação de TBARS em fígado de ratos}

Oteste do TBA, modificado por Cecchini, Aruoma e Halliwell (1990), foi utilizado para quantificação de lipoperóxidos conforme procedimento descrito a seguir. Um $\mathrm{mL}$ do homogenato foi misturado a $0,2 \mathrm{~mL}$ de água destilada, $1 \mathrm{~mL}$ de TCA $(28 \%)$ e 1 $\mathrm{mL}$ de TBA (1\% em NaOH $50 \mathrm{mM})$. Para os tubos em que a reação de lipoperoxidação foi acelerada por ferro e ácido ascórbico (FeIII/Ac. Asc.), foram adicionados $0,1 \mathrm{~mL}$ de cloreto férrico $(1 \mathrm{mM})$ e 0,1 $\mathrm{mL}$ de ácido ascórbico $(1 \mathrm{mM})$. Após adição de todos os componentes os tubos foram homogeneizados em vortex, incubados a $95^{\circ} \mathrm{C}$ por 15 minutos, transferidos para banho de gelo por aproximadamente 5 minutos. A extração foi realizada pela adição de $2 \mathrm{~mL}$ de butanol, agitação no vortex por 40 segundos e centrifugação (centrífuga refrigerada - K70 D) a $3000 \mathrm{rpm}$ por 20 minutos. A leitura foi realizada em espectrofotômetro Varian/série 634 S, com luz visível, fenda de 1,0 nm, nos comprimentos de onda de 535 e $572 \mathrm{~nm}$. O teste foi realizado em duplicata para cada reação e a lipoperoxidação foi avaliada pela formação de substâncias reativas ao ácido tiobarbitúrico (TBARS) e expressas em nmoles/g fígado. 
Ensaio de FOX (Complexo Fe(III)-Xilenol Laranja)

O fígado foi homogeneizado (homogeneizador Potter) na proporção de $100 \mathrm{mg}$ para $10 \mathrm{~mL}$ de metanol (grau de pureza HPLC) e centrifugado (centrífuga refrigerada - K70 D) a $2000 \mathrm{rpm}$ por 10 minutos. Após, as reações foram preparadas com: $500 \mu \mathrm{L}$ de $\mathrm{FeSO}_{4}(1 \mathrm{mM}), 200 \mu \mathrm{L}$ de $\mathrm{H}_{2} \mathrm{SO}_{4}$ $(0,25 \mathrm{M}), 200 \mu \mathrm{L}$ de xilenol $(1 \mathrm{mM}), 1000 \mu \mathrm{L}$ de água e $100 \mu \mathrm{L}$ de amostra. Foram incubadas por 24 horas e quantificadas em espectrofotômetro Varian/série $634 \mathrm{~S}$ em $560 \mathrm{~nm}$ contra água. Após esta leitura, foi adicionado aos tubos $5 \mu \mathrm{L}$ de hidroperóxido de cumeno (CHP) seguido de incubação por 30 minutos e nova leitura em 560 $\mathrm{nm}$. Os níveis de hidroperóxidos lipídicos foram expressos em equivalentes de hidroperóxido de cumeno em nmoles $\mathrm{CHP} / \mathrm{g}$ fígado. A quantidade de hidroperóxido é baseada nos hidroperóxidos que reagem com o íon metálico $\mathrm{Fe}(\mathrm{II})$. O hidroperóxido é reduzido e o ferro é oxidade em $\mathrm{Fe}$ (III) que forma um complexo com o Xilenol (HERMES-LIMA; WILLMORE; STOREY, 1995).

\section{Análise histológica}

Fragmentos do lóbulo hepático mediano de diferentes grupos animais, foram fixados em formalina tamponada $10 \%$, processados e corados por Hematoxilina e Eosina (HE). As lâminas foram examinadas, às cegas, por dois observadores e a quantificação de eventual hemorragia e/ou necrose centro-lobular foi realizada pela observação de 10 campos, utilizando o seguinte critério: 0 (ausente), $1+$ (discreta), 2+ (moderada), 3+ (acentuada) (ESTEVÃO; SAITO; GUALTIERI, 2002).

\section{Análise estatística}

Para avaliar os diferentes grupos experimentais, foi utilizada a Análise de Variância (ANOVA), e para comparação entre as médias foi utilizado o Teste de Tukey. Foram considerados como estatisticamente significativos os valores de $\mathrm{p}<0,05$.

\section{Resultados}

Na tabela 1, temos os resultados dos parâmetros: peso relativo do fígado por $100 \mathrm{~g}$ de animal, avaliação da atividade enzimática das transaminases, quantidade de ECV ingerida em média por animal, total de ECV consumido por animal no final do experimento e escores de necrose e hemorragia dos grupos tratados ou não com ECV.

Tabela 1. Parâmetros nutricionais, bioquímicos e histopatológicos dos animais.

\section{Parâmetros}

\begin{tabular}{|c|c|c|c|c|c|c|c|}
\hline Grupos & $\begin{array}{c}\text { Peso do fígado } \\
/ 100 g \text { de rato }(\%)\end{array}$ & $\begin{array}{c}\mathbf{A S T} \\
(\mathbf{U} / \mathbf{L})\end{array}$ & $\begin{array}{l}\text { ALT Con } \\
(\mathbf{U} / \mathbf{L})\end{array}$ & $\begin{array}{l}\text { c. de extrato/ } \\
\text { dia(mg) }\end{array}$ & $\begin{array}{c}\text { Total de extrato/ } \\
\text { rato }(\mathrm{mg})\end{array}$ & Hemorragia & Necrose \\
\hline$\overline{\mathrm{G} 1(6)}$ & $4,3 \pm 0,5 \mathrm{a}$ & $28,2 \pm 1,4 \mathrm{~b}$ & $23,6 \pm 1,7 b$ & * & * & 0 & 0 \\
\hline $\mathrm{G} 2(6)$ & $2,5 \pm 0,4 \mathrm{c}$ & $378,5 \pm 97,1 \mathrm{a}$ & $457,4 \pm 131,3 \mathrm{a}$ & * & * & $2,0 \pm 0,4 \mathrm{a}$ & $2,8 \pm 0,2 \mathrm{a}$ \\
\hline G3(6) & $3,5 \pm 0,2 b$ & $30,0 \pm 2,6 b$ & $24,3 \pm 1,3 b$ & $0,9 \pm 0,2 \mathrm{a}$ & $30,9 \pm 5,1 \mathrm{a}$ & 0 & 0 \\
\hline G4(6) & $2,6 \pm 0,3 c$ & $337,5 \pm 88,4 \mathrm{a}$ & $380,0 \pm 141,3 \mathrm{a}$ & $0,9 \pm 0,2 \mathrm{a}$ & $30,6 \pm 5,1 \mathrm{a}$ & $1,7 \pm 0,3 \mathrm{a}$ & $2,5 \pm 0,2 \mathrm{a}$ \\
\hline
\end{tabular}

Grupo 1 - grupo controle; Grupo 2 - animais inoculados com DEN; Grupo 3 - animais tratados com ECV; Grupo 4 - animais tratados com ECV e inoculados com DEN; (6) número de animais por grupo; intensidade de hemorragia e necrose: 0 = ausente, $1=$ discreta, $2=$ moderada, 3 = acentuada; média \pm erro padrão; médias seguidas por letras distintas diferem significativamente entre si em nível de $\mathrm{p}<0,05$ (Teste de Tukey). 
$\mathrm{Na}$ Figura 1A, temos a dosagem da atividade das enzimas AST dos grupos G1 a G4, onde G2 e G4, não apresentaram resultados estatisticamente significativos. No entanto, nos resultados da Figura 1B, a dosagem da atividade enzimática da
ALT do grupo G4 (tratado com ECV e submetido ao DEN) apresentou resultados estatisticamente significativos: os valores encontrados são inferiores aos do grupo G2, e isso indica uma menor lesão e com isso uma tendência à quimioproteção do ECV.

Figura 1. Identificação de lesão celular por meio da dosagem da atividade das enzimas AST/ALT. Grupo 1 - grupo controle; Grupo 2 - animais inoculados com DEN; Grupo 3 - animais tratados com ECV; Grupo 4 - animais tratados com ECV e inoculados com DEN; média \pm erro padrão; médias seguidas por letras distintas diferem significativamente entre si em nível de $\mathrm{p}<0,05$ (Teste de Tukey), $(\mathrm{n}=6)$.

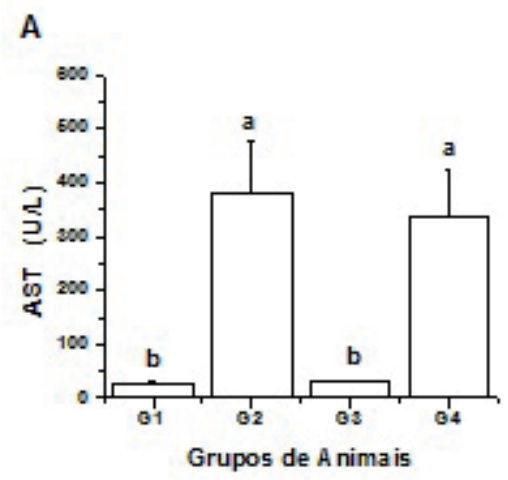

$\mathrm{Na}$ Figura 2 consta a quantificação das substâncias reativas ao ácido tiobarbitúrico (TBARS) dos grupos G1 a G4, nos quais G2 e G4 apresentaram resultados não significativos. Porém, pode se observar que os valores do grupo G4 foram inferiores aos valores do grupo G2, e isso indica
B

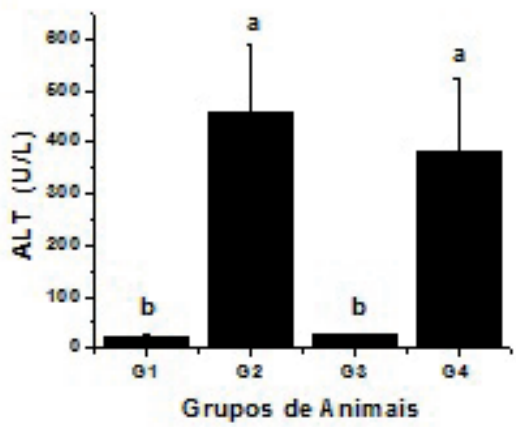

uma menor lipoperoxidação no grupo G4 devido a ação do ECV e confirma a ação antioxidante do chá verde. Esses resultados encontrados fortalecem o resultado das transaminases que, mesmo não sendo significativos, mantêm a tendência de quimioproteção no grupo G4.

Figura 2. Níveis de lipoperoxidação por meio da quantificação de TBARS nos animais pertencentes aos diferentes grupos. Grupo 1 - grupo controle; Grupo 2 - animais inoculados com DEN; Grupo 3 - animais tratados com ECV; Grupo 4 - animais tratados com ECV e inoculados com DEN; média \pm erro padrão; médias seguidas por letras distintas diferem significativamente entre si em nível de $\mathrm{p}<0,05$ (Teste de Tukey), $(\mathrm{n}=6$ ).

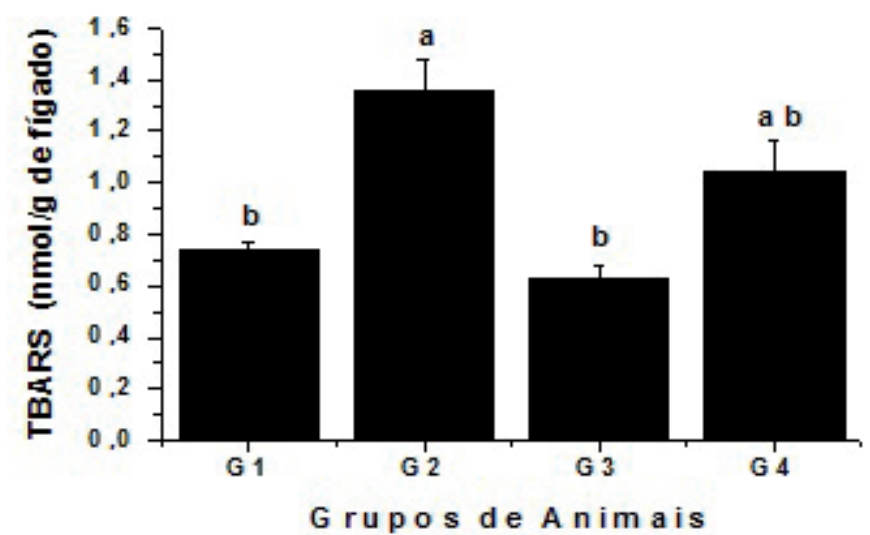


Os resultados da Figura 3 não apresentam diferenças significativas entre os grupos, pois o pico do valor de FOX é encontrado após 24 h da ação do DEN, decaindo rapidamente logo em seguida, como os ratos foram sacrificados $48 \mathrm{~h}$ após inoculação da DEN, mesmo sendo avaliados nestes grupos os valores de FOX não são conclusivos.

Figura 3. Níveis de lipoperoxidação por meio da quantificação do Complexo Fe(III)-Xilenol Laranja (FOX) nos animais pertencentes aos diferentes grupos. Grupo 1 - grupo controle; Grupo 2 - animais inoculados com DEN; Grupo 3 - animais tratados com ECV; Grupo 4 - animais tratados com ECV e inoculados com DEN; média \pm erro padrão; médias seguidas por letras distintas diferem significativamente entre si em nível de $\mathrm{p}<0,05$ (Teste de Tukey), $(\mathrm{n}=6)$.

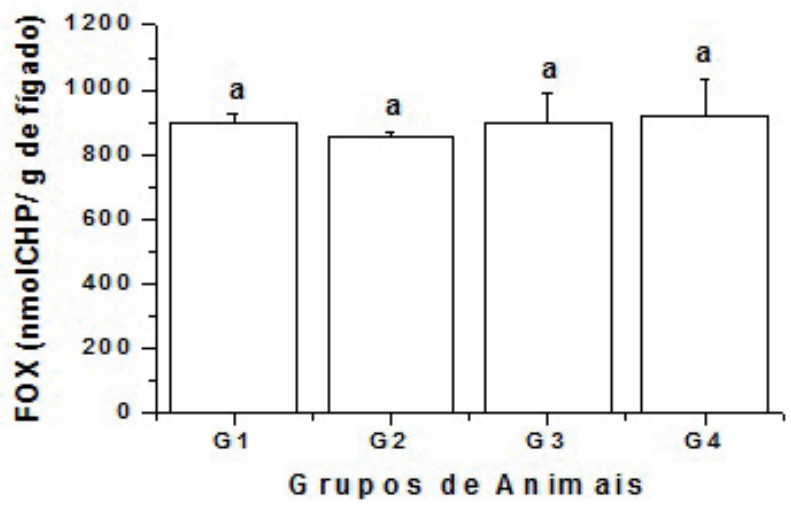

Na Fig. 4, temos os cortes histopatológico dos grupos G1 a G4; a imagem G1 visualiza a região centro-lobular de tecidos do grupo controle; a imagem G2 visualiza uma região com foco de necrose do grupo submetidos ao DEN; a imagem G3 visualiza tecidos do fígado dos ratos tratados somente com ECV; a imagem G4 visualiza uma região com foco de necrose no fígado dos ratos tratados com ECV e intoxicados com DEN. Mesmo não sendo significativas, as imagens dos cortes mostram uma pequena diferença no tamanho dos focos de necrose nos animais tratados previamente com o ECV.

Figura 4. Estudo histopatológico do tecido hepático dos animais pertencentes aos diferentes grupos. Corte G1 - região centro-lobular do fígado dos ratos controles; corte G2 - região com foco de necrose no fígado dos ratos 48 h após inoculação do DEN; corte G3 - tecido do fígado dos ratos tratados somente com ECV; corte G4 - região com foco de necrose no fígado dos ratos tratados com ECV e intoxicados com DEN. Coloração de hematoxilina e eosina; aumento de 400X no microscópio óptico, seta indica foco de necrose.

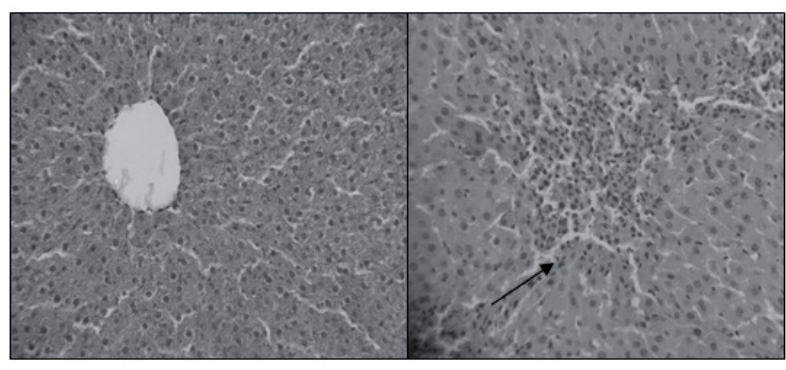

G 1
G 2

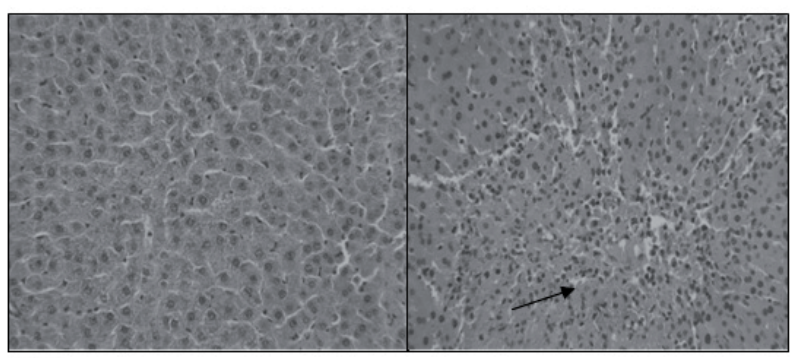

G 4 


\section{Discussão}

Uma das principais aplicações do chá verde é a sua capacidade antioxidante. Tendo em vista esta propriedade quimioprotetora, utilizouse um conhecido agente químico a DEN, cujo mecanismo de ação envolve a formação de radicais livres e citotoxicidade. Para avaliar a possível quimioproteção do ECV, foram utilizados vários parâmetros bioquímicos como: dosagem das enzimas hepáticas (AST/ALT) para medir o grau de lesão celular, quantificação do TBARS e FOX para medir a lipoperoxidação de membranas e o histopatológico para verificar alterações morfológicas das células.

As ações antioxidante e quimioprotetora vêm sendo estudadas com maior interesse pelos pesquisadores nos últimos anos. Para a avaliação de sua atividade quimioprotetora, Cheng et al. (1991); Katiyar et al. (1993); Tamura et al. (1997), têm utilizado diferentes protocolos experimentais. Tendo em vista esses experimentos, utilizamos um protocolo de longa duração para testar a atividade quimioprotetora do chá verde quando ingerido por longos períodos, observando se ocorre proteção efetiva ou não.

Nos resultados da tabela 1 , os animais G2 apresentam pesos relativos do fígado significativamente menores quando comparados ao G1. Esses valores indicam a presença de lesão hepática nesses animais, pois a diminuição do peso relativo é indicativo de destruição tecidual e lesão hepática. $\mathrm{O}$ grupo G4 apresentou uma tendência que indicaria uma pequena proteção, quando comparado com o G2, indicando uma menor lesão e destruição hepática.

Os valores de AST/ALT do grupo G4 não foram estatisticamente significativos quando comparados com o G2, mas demonstram claramente uma tendência de quimioproteção, pois os valores aumentados da atividade enzimática das transaminases indicam lesão celular. Sua diminuição está diretamente relacionada com o grau de proteção apresentado pela ação do chá verde sobre as células hepáticas. Os valores de AST/ALT dos grupos G1 e G3 são semelhantes entre si e indicam que o ECV não causa lesão celular nas doses testadas neste experimento, que são doses próximas às ingeridas pelas pessoas que tem o hábito de consumir o chá verde.

O resultado do nível de hemorragia e necrose dos grupos G2 e G4 não foram significativos quando comparados entre si. Mas novamente observamos que os resultados do grupo G4, tratado com ECV, são inferiores aos do grupo G2 confirmando os valores encontrados na dosagem das transaminases, fortalecendo a sugestão de proteção pelo ECV.

Pode-se observar a ação quimioprotetora do ECV frente ao DEN, na dosagem do ácido tiobarbitúrico (TBARS), que é utilizado para demonstrar a lipoperoxidação das membranas celulares (Fig. 2). Os resultados indicam uma tendência de queda da lipoperoxidação das membranas no G4, confirmando a ação antioxidante do chá verde. Os animais que tomaram chá verde e foram intoxicados com DEN apresentaram uma lipoperoxidação menor que nos animais que não foram tratados com o chá verde. Esses resultados fortalecem a utilização do chá como um antioxidante importante, capaz de proteger as células contra a ação dos radicais livres, que são espécies químicas que possuem um único elétron não-pareado em uma órbita externa (HALLIWELL; GUTTERIDGE, 1999). Os resultados encontrados por Jun et al. (2002), Saffari e Sadrzadeh (2004) também sugerem um efeito antioxidante do chá verde, diminuindo a lipoperoxidação em membranas celulares, sendo Jun et al. (2002) especificamente em microssomas hepáticos.

$\mathrm{Na}$ dosagem de FOX (Fig. 3), não houve diferenças significativas entre os valores encontrados nos grupos G2 e G4. Uma explicação para os resultados não apresentarem diferenças é que os animais foram sacrificados $48 \mathrm{~h}$ após a inoculação da DEN e estudos realizados por Estevão, Saito e Gualtieri (2002) demonstraram que o pico do FOX 
é encontrado 24h após a inoculação da DEN e decaindo rapidamente nas horas seguintes.

O estudo histopatológico dos Grupos G1 e G3 mostra que aparentemente não houve diferença morfológica entre o tecido observado nesses grupos, e isso indica que o consumo de chá verde nas doses estabelecidas por este experimento não provoca lesão hepática observável tanto em corte histológico, como por dosagem da atividade das enzimas AST/ALT. Na comparação entre o histopatológico dos Grupos G2 a G4, fica demonstrado que o ECV pode proteger as células hepáticas do agente lipoperoxidante (DEN), pois morfologicamente também houve uma tendência à diminuição dos focos de necrose no grupo G4 tratado com ECV previamente antes da inoculação da DEN. A região com foco de necrose na imagem do grupo G4 é ligeiramente menor que do corte do grupo G2, demonstrando que houve uma proteção pelo ECV, mesmo que pequena.

O uso do chá verde remonta há séculos e é uma das bebidas mais consumidas e de fácil aceitação no mundo todo (CHEN et al., 1997). Mas foi somente há poucos anos que o chá se tornou um objeto de estudo da comunidade cientifica mundial, sendo seu consumo associado com vários benefícios à saúde. Utilizando um agente lipoperoxidante e hepatotóxico (DEN) e realizando testes para quantificar as lesões causadas por este agente (AST/ ALT, TBARS, FOX e histopatológico) e verificar que o chá verde pode agir como antioxidante e quimioprotetor nas condições testadas. Analisando os resultados encontrados, pode-se dizer que o ECV demonstrou ter uma ação protetora contra a ação da DEN, mesmo que utilizado em pequenas doses como foi o caso deste experimento. Um ponto interessante é que o tempo de meia vida do ECV é maior do que o tempo de meia vida de suas catequinas isoladamente (CHEN et al., 1997). Isso fortalece o uso do extrato como agente protetor e não de suas catequinas, pois quanto maior o tempo de meia vida, maior o tempo de ação dos compostos no organismo.
Os resultados encontrados não foram significativos, mas os principais resultados indicaram uma tendência à diminuição da lesão nos animais tratados previamente pelo ECV a depois intoxicados com a DEN. É importante ressaltar que a dosagem utilizada para a DEN é muito maior que a dosagem do ECV e que no dia a dia as pessoas não são expostas a doses tão elevadas de agentes tóxicos e sim a pequenas doses que vão levando ao acúmulo de lesões nas nossas células. Portanto, o uso do chá verde mesmo em pequenas doses, como o realizado neste teste, pode trazer benefícios para a saúde. Ele protege principalmente contra as pequenas lesões do dia-a-dia causadas pela ação dos radicais livres.

Além da ação direta como antioxidante, o uso prolongado do chá verde pode levar ao estímulo das enzimas do complexo do citocromo P450, favorecendo um metabolismo mais eficiente associado a uma conjugação mais rápida, diminuindo o tempo de ação dos intermediários reativos no organismo, pois a ação dos intermediários reativos é um fator importante na indução química de neoplasias (MALIAKAL; COVILLE; WANWIMOLRUK, 2001). Portanto, a associação desta ação indireta com a capacidade de inibir radicais livres, pode ser um grande trunfo para a diminuição das carcinogênese química.

Apesar dos resultados obtidos colaborarem com a utilização do chá como um agente protetor importante, maiores estudos são necessários para compreender os mecanismos envolvidos nesses processos e para um promissor emprego do extrato do chá verde como possíveis adjuvantes no tratamento de doenças hemolíticas, doenças crônicas e na quimioterapia de câncer.

\section{Agradecimentos}

Ao Departamento de Patologia da UEL e seus professores que possibilitaram a realização deste experimento. 


\section{Referências}

CAI, Y. J.; MA, L. P.; HOU, L. F.; ZHOU, B.; YANG, L.; LIU, Z. L. Antioxidant effects of green tea polyphenols on free radical initiated peroxidation of rat liver microsomes. Chemistry and Physics of Lipids, Limerick, v. 120, p. 109-117, 2002.

CECCHINI, R.; ARUOMA, O. I.; HALLIWELL, B. The action of hydrogen peroxide on the formation of thiobarbituric acid-reative material from microssomes or from DNA damage by bleomycin or phenamthroline. Artefactis in the thiobarbituric acid test. Free Radical Research Communications, New York, v. 10, p. 245-258, 1990.

CHEN, J. H.; TIPOE, G. L.; LIONG, E. C.; SO, H. S.; LEUNG, K. M.; TOM, W. M.; FUNG, P. C.; NANJI, A. Green tea polyphenols prevent toxin-induced hepatotoxicity in mice by down-regulating inducible nitric oxide-derived prooxidants. American Journal of clinical Nutrition, New York, v. 80, p. 742-751, 2004.

CHEN, L.; LEE, M. J.; LI, H.; YANG, C. S. Absorption, distribution, and elimination of tea polyphenols in rats. Drug Metabolism and Disposition, Baltimore, v. 25, n. 9 , p. 1045-1050, 1997.

CHENG, S.; DING, L.; ZHEN, Y.; LIU, P.; ZHU, Y.; CHEN, Y.; HU, X.. Progress in studies on the antimutagenicity and anticarcinogenicity of green tea epicatechins. Chinese Medical Sciences Journal, London, v. 6, n. 4, p. 233-238, 1991.

COOK, N. C.; SAMMAN, S. Flavonoids-Chemistry, metabolism, cardioprotective effects, and dietary sources. Journal of Nutritional Biochemistry, Stoneham, v. 7, p. 66-76, 1996.

ELOFF, J. N. Which extractant should be used for the screening and isolation of antimicrobial components from plants? Journal of Ethnopharmacology, Lausanne, v. 60 , p. $1-8,1998$.

ESTEVÃO, D.; SAITO, A. Y.; GUALTIERI, K. A. Proctetive effect by diethyldithilcarbamate on hepatocytic and preneoplastic foci induced by diethylnitrosamine. Biosaúde, Londrina, v. 4, n. 1, p. 37-50, 2002.

HALLIWELL, B.; GUTTERIDGE, J. M. C. Free radicals in biology and medicine. 3. ed. Oxford: University Press, 1999.

HERMES-LIMA, M.; WILLMORE, W. G.; STOREY, K. B. Quantification of lipid peroxidation in tissue based on the Fe(III)Xylenol orange complex formation. Free Radical Biology \& Medicine, New York, v. 19, p. 271280, 1995.

JUN, Y.; LAN, P. M.; LI, F. H.; BO, Z.; LI, Y.; ZHONG,
L. L. Antioxidant effects of green tea polyphenols on free radical initiated peroxidation of rat liver microsomes. Chemistry and Physics of Lipids, Limerick, v. 120, p. 109-117, 2002.

KATIYAR, S. K.; AGARWAL, S. K.; ZAIM, M. T.; MUKHTAR, H. Protection against N-nitrosodiethylamine and benzo[a]pyrene-induced forestomach and lung tumorigenesis in A/J mice by green tea. Carcinogenesis, Oxford, v. 14, n. 5, p. 849-855, May, 1993.

LEE, M. J.; MALIAKAL, P.; CHEN, L.; MENG, X.; BONDOC, F. Y.; PRABHU, S.; LAMBERT, G.; MOHR, S.; YANG, C. S. Pharmacokinetics of tea catechins after ingestion of green tea and (-)-epigallocatechin-3-gallate by humans: formation of different metabolites and individual variability. Cancer Epidemiology Biomarkers \& Prevention, Philadelphia, v. 11, p. 1025-1032, Oct. 2002.

MALIAKAL, P. P.; COVILLE, P. F.; WANWIMOLRUK, $\mathrm{S}$. Tea consumption modulates hepatic drug metabolizing enzymes in Wistar rats. Journal of Pharmacy and Pharmacology, London, v. 53, n. 4, p. 569-577, Apr. 2001.

MIYAZAWA, T. Absorption, metabolism and antioxidative effects of tea catechin in humans. Biofactors, Oxford, v. 13, p. 55-59, 2000.

NAKAGAWA, T.; YOKOZAWA, T. Direct scavenging of nitric oxide and superoxide by green tea. Food and Chemical Toxicology, Oxford, v. 40, p. 1745-1750, 2002.

PAQUAY, J. B.; HAENEN, G. R.; STENDER, G.; WISEMAN, S. A.; TIJBURG, L. B.; BAST, A. Protection against nitric oxide toxicity by tea. Journal of Agricultural and Food Chemistry, Easton, v. 48, p. 57685772, Nov. 2000.

REITMAN, S.; FRANKEL, S. A. Colorimetric method for the determination of serum glutamic oxalacetic and glutamic pyruvic transaminases. American Journal of Clinical Pathology, Philadelphia, v. 28, p. 56-63, 1957.

RICE-EVANS, C. A.; MILlER, N. J.; PAGANGA, G. Structure-antioxidant activity relationships of flavonoids and phenolic acids. Free Radical Biology \& Medicine, New York, v. 20, p. 933-956, 1996.

SAFFARI, Y.; SADRZADEH, S. M. Green tea metabolite EGCG protects membranes against oxidative damage in vitro. Life Science, Varanasi, v. 74, p. 1513-1518, Feb. 2004.

SÁNCHEZ-PÉREZ, Y.; CARRASCO-LEGLEU, C.; GARCÍA-CUELLAR， C.; PÉREZ-CARREÓN， J.; HERNÁNDEZ-GARCÍA, S.; SALCIDO-NEYOY, M.; ALEMÁN-LAZARINI, L.; VILLA-TREVIÑO, Saúl. 
Oxidative stress in carcinogenesis. Correlation between lipid peroxidation and induction of preneoplastic lesions in rat hepatocarcinogêneses. Cancer Letters, Amsterdam, v. 217, n. 1, p. 25-32, Jan. 2005.

SCOTT, G. N.; ELMER, G. W. Update on natural product-drug interactions. American Journal of HealthSystem Pharmacy, Bethesda, v. 59, n. 4, p. 339-347, Feb. 2002.

SIDDIQUI, I. A.; AFAQ, f.; ADHAMI, V. M.; AHMAD, N.; MUKHTAR, H. Antioxidants of the beverage tea in promotion of human health. Antioxidants \& Redox Signaling, New York, v. 6, p. 571-582, June 2004.

SKRZYDLEWSKA, E.; OSTROWSKA, J. ; FARBISZEWSKI, R.; MICHALAK, K. Protective effect of green tea against lipid peroxidation in the rat liver, blood serum and the brain. Phytomedicine, Jena, v. 9, p. 232-238, Apr. 2002.

SUNG, H.; NAH, J.; CHUN, S.; PARK, H.; YANG, S. A.; MIN, W. K. In vivo antioxidant effect of green tea. European Journal of clinical Nutrition, London, v. 54, p. 527-529, Jul. 2000.

TAMURA, K.; NAKAE, D.; HORIGUCHI, K.; AKAI, H.; KOBAYASHI, Y.; SATOH, H.; TSUJIUCHI, T.; DENDA, A.; KONISHI, Y. Inhibition by green tea extract of diethylnitrosamine-initiated but not choline-deficient, L-amino acid-defined diet-associated development of putative preneoplastic, glutathione S-transferase placental form-positive lesions in rat liver. Japanese Journal of Cancer Research, Tokyo, v. 88, n. 4, p. 356362, 1997.

YANAGIMOTO, K.; OCHI, H.; LEE, K. G.; SHIBAMOTO, T. Antioxidative activities of volatile extracts from green tea, oolong tea, and black tea. Journal of Agricultural and Food Chemistry, Easton, v. 51, p. 7396-7401, Dec. 2003.

YOKOZAWA, T.; CHO, E. J.; HARA, Y.; KITANI, K. Antioxidative activity of green tea treated with radical initiator 2, 2'-azobis(2-amidinopropane) dihydrochloride. Journal of Agricultural and Food Chemistry, Easton, v. 48, p. 5068-5073, Oct. 2000.

ZHU, M.; CHEN, Y.; LI, R. C. Oral absorption and bioavailability of tea catechins. Planta Medica, Stuttgart, v. 66 , p. 444-447, June 2000.

Recebido em 17 de outubro de 2010 - Received on October 17, 2010

Aceito em 11 de novembro de 2010 - Accepted on November 11, 2010 
